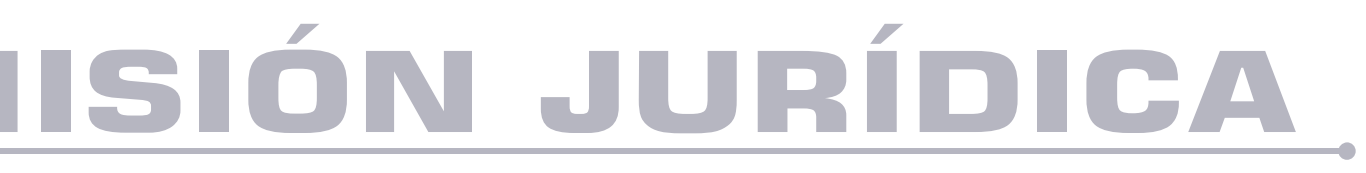

\title{
Conflicto y violencia sociopolíticos vistos por el modelo centro-periferia
}

Sociopolitical conflict and violence analyzed with the center - periphery model

Autor: Marguerite Wotto

DOl: https://doi.org/10.25058/1794600X.1000

\footnotetext{
SP MISIÓN JURÍDICA A 


\section{CONFLICTO Y VIOLENCIA SOCIOPOLÍTICOS VISTOS POR EL MODELO CENTRO-PERIFERIA*}

\author{
SOCIOPOLITICAL CONFLICT AND \\ VIOLENCE ANALYZED WITH THE \\ CENTER - PERIPHERY MODEL
}

CONFLITO E VIOLÊNCIA

SOCIOPOLÍTICA VISTOS PELO

MODELO DE CENTRO-PERIFERIA

\section{RESUMEN}

Conflicto y violencia, dos palabras muy comunes, muy importantes para la conciencia individual y colectiva, son conceptos empleados en el lenguaje común para significar y normar malestares de grados diversos. En consecuencia, son a menudo confundidas cuando viene el momento de describir ciertos hechos y gestos. Este artículo propone una definición de estos conceptos, además de estudia la particularidad que ellos aportan al análisis de lo político en un contexto específico. A la luz del modelo centro-periferia, se analizan los factores importantes que influyen en las manifestaciones de los conceptos.

\section{PALABRAS CLAVE}

Conflicto; violencia; colectiva; política; centro-periferia

\section{*Artículo de reflexión.}

a. Dr. Marguerite Wotto, Profesora asociada al Departamento de la Educación Especializada de Université du Québec à Montreal (DEFS-UQAM), Coordinadora y el Investigadora en el Centro interdisciplinario de investigación y desarrollo sobre el aprendizaje de toda la vida (CIRDEF-UQAM) 


\section{ABSTRACT}

Conflict and violence are two words that are very common, very important for the individual and collective conscience. These are two concepts used in everyday language to stand for and to standarize discomforts of varying degrees. Consequentially, they are often confused when describing certain facts and actions. This article proposes a definition of these concepts. It studies the singularity that each provide to a political analysis in a specific context. In the light of the center-periphery model examines the important factors that influence these concepts manifestations.

\section{KEY WORDS}

Conflict; violence; collective; politic; center-periphery

\section{RESUMO}

Conflito e violência, duas palavras muito comuns, muito importantes para a consciência individual e coletiva são dois conceitos utilizados em linguagem comum para significar e regular desconfortos de diferentes graus. Como resultado, eles são frequentemente confundidos quando se trata de descrever certos fatos e gestos. Este artigo propõe uma definição desses conceitos. Estudar a particularidade de que eles contribuem para a análise do político em um contexto específico. À luz do modelo de periferia central, analisa os fatores importantes que influenciam as manifestações dos conceitos.

\section{PALAVRAS-CHAVE}

Conflito; violencia; ação coletiva; política; centro-periferia

\section{INTRODUCCIÓN}

Conflicto y violencia son dos conceptos frecuentemente utilizados para describir numerosas acciones y comportamientos que van en contra de la de paz, la tranquilidad, la armonía y la seguridad. Estas acciones se manifiestan en diferentes espacios y actores como: personas, familia, parejas, grupos rivales, lugares de trabajo, entre gobernantes y organizaciones sociales, y entre el gobierno y la sociedad. Estos comportamientos no deseados han sido ampliamente estudiados por las ciencias humanas (psicología, sociología, antropología, comunicación, etc.), pero es bajo el ángulo político que se analizarán en este escrito.

Según Amnesty International, numerosos dirigentes en muchas partes del mundo multiplicaron los discursos de odio y de miedo que favorecían el desarrollo de una retórica de « nosotros contra ellos». El organismo en su informe de 2017 y 2018, comprueba que muchos de estos discursos amenazan directamente los derechos y las libertades de millares de personas, ya que proclaman el miedo, la acusación y la división y se ensañan con grupos enteros de población.

La violencia y el conflicto son nociones generalmente confundidas por la prensa y las personas del común, sobre todo cuando se habla de política. Representan, en efecto, el punto de anclaje de una multitud de análisis políticos, aunque los significados que les son concedidos sean variables. Sin embargo, debemos clarificar estos conceptos en su sentido real ¿Qué es el conflicto y qué es la violencia? ¿Cuáles son las particularidades de cada uno de estos conceptos?, ¿Si consideramos que estos fenómenos participan en la restructuración sociopolítica, nos permiten hacer una entrega en la estructuración de lo político?, ¿Cómo afectan la política y cuál lectura nos permiten hacer si consideramos el modelo centro-periferia? Estas son las preguntas fundamentales que intentamos responder en las tres partes que conforman este artículo. La primera parte intenta clarificar los conceptos fundamentales conflicto y violencia. La segunda, propone una problemática y estructura de la argumentación alrededor de la violencia social y política. Y finalmente, se proponen cimientos de un modelo de lectura de lo político, apoyándose esencialmente en las dimensiones de: el centro, los lugares de expresión, lo imaginario y la figura del pueblo.

\section{DEFINICIÓN DE LOS CONCEPTOS}

\section{1. El conflicto}

El Observatorio Permanente de Riesgos Psicosociales, considera que: "el conflicto es primordialmente un problema de percepción, pudiendo encontrar que una de las partes afectadas no percibe que la otra le afecta negativamente" (2008: 6). Ciertamente, podemos expresar nuestra comprensión de la violencia con los mismos términos y darle el mismo sentido. 
Como lo subraya Chevalier (1978), "la naturaleza, el individuo y la sociedad se producen y reproducen en/por el conflicto, rompiéndose ellos mismos entre principios antagónicos de funcionamiento» (p. 4). Así, el conflicto es un estado permanente del medio social que se manifiesta en varios niveles. Bélanger y Lemieux (1996) lo definen como una relación social que se presenta bajo la forma de una secuencia de acciones, que resulta del rechazo de un actor por estar sometido a control, y de la persistencia del otro actor, a quién se lo impone. Según el análisis de estos autores, el conflicto representa las situaciones de tensiones y de dependencia que animan la acción colectiva y la capacidad diferenciada por los individuos llamados a sostener y vivir estas situaciones.

El Observatorio Permanente de Riesgos Psicosociales considera que la aparición de un conflicto está determinada por una serie de elementos como: la existencia de posiciones, intereses y necesidades enfrentadas; la necesidad de la intervención y/o percepción de dos o más partes; la existencia y/o aparición de emociones: frustración, tensión, enfado, etc. Esta organización subraya que los efectos negativos que conlleva un conflicto son: descontento, tensión y hostilidad pudiendo desencadenar en estrés; bloqueo y dificultad en la comunicación; incremento de las diferencias entre las partes: se tiende a ver al otro como un rival, como un enemigo y conduciendo a comportamientos destructivos (Observatorio Permanente de Riesgos Psicosociales, 2008).

Según su causa se observan numerosos tipos de conflictos, entre los que se distinguen: el conflicto intrapersonal, cuyo origen se encuentra en la propia persona debido a valores contradictorios -por ejemplo: se nos pide en el trabajo que realicemos algo que va en contra de nuestras creencias-; el conflicto interpersonal que implica varias partes; el conflicto intragrupal que interviene entre los miembros de un grupo; el conflicto interorganizacional que sobreviene entre organizaciones; el conflicto relacional que tiene su origen en una falta de comunicación; el conflicto de información; el conflicto armado, entre otros. Para Barrera el conflicto político sugiere cuatro tipos de circunstancias:

1. Cuando al interior de una sociedad un grupo ha sido excluido o exige su reconocimiento dentro de la asociación política.
2. Cuando la presencia de otro grupo social altera el orden y provoca el replanteamiento de la identidad propia, causando un encuentro con violencia para eliminar al oponente.

3. Cuando un grupo dentro del orden social se inconforma con el lugar o la función que se le ha designado.

4. Cuando se plantea la posible reforma del consenso jurídico social. En este punto identificamos la denominada reforma del Estado, que tanto asusta pero que no es nada nuevo (Barrera, 2008: 54).

Este último punto nos devuelve al sentimiento que tenemos delante un acto de violencia, podemos, incluso, concluir que ciertos efectos del conflicto son manifestaciones de la violencia. Pero, ¿qué representa la violencia?, o simplemente ¿qué es la violencia?

\section{La violencia}

Moreno (2009) considera que la violencia es un tema complejo de investigación para las ciencias sociales, representa un reto desde su conceptualización misma, por cuanto los debates teóricos sobre la inherencia de la violencia en los seres humanos o su aprendizaje social no están todavía acabados. La autora ha añadido que, como concepto, no se trata de algo estático pues su significado varía según el tiempo, la sociedad o la cultura desde la cual se define, no obstante, el ejercicio desigual del poder es la constante en la definición y su presencia en todo el mundo, en sus diferentes formas, es un hecho.

Esta consideración es compartida por Martín (2004) al afirmar que: "la violencia es una regulación de los conflictos discriminatoria y perjudicial" (p. 224). El autor subraya que las explicaciones e interpretaciones que se han dado sobre la violencia varían de acuerdo con patrones personales, culturales, ideológicos o simbólicos. En este sentido es posible decir que la violencia podría ser vivenciada como la ruptura de un «orden establecido», de una armonía preexistente, de unas condiciones de vida en las que se cifran las expectativas de existencia de la especie humana. Esto se debe a que, frente a los diversos proyectos y objetivos que existen para regular los conflictos, se opta por discriminar el usufructo de los recursos disponibles perjudicando innecesariamente a alguna de las partes. Los dos autores reconocen que cuando se refieren a la 
violencia se trata de la justicia, de los derechos humanos, si ella no existiera probablemente no hablaríamos de la paz.

La violencia desde el derecho ha sido estudiada por numerosos autores desde dos corrientes de pensamiento: el derecho natural y el derecho positivo. Según Benjamín (2012) quien hizo una crítica filosófica de la violencia, el concepto de violencia se definió por dos dimensiones fundamentales: los fines y los medios. Estas dos dimensiones son tanto identificadas por el derecho natural como el derecho positivo. Infortunadamente para el autor esta consideración no permite decir cuál es el premio y cuál es el fin. El autor afirma que el criterio esencial de toda investigación sobre la violencia es la de legitimidad, sin embargo, el significado de la distinción de la violencia legítima e ilegítima no es evidente así no más. Hay que tomar en cuenta también otros criterios, sin necesariamente insistir sobre las mismas dimensiones, hay que definir la violencia para incluir allí tanto al que tiene la percepción de afectado como al que la ejerce.

Molina y Muñoz (2004) clasifican la violencia según ciertas dimensiones, indicando que hay que reconocer que aunque el conflicto y la violencia son dos fenómenos de naturaleza diferente, ambos se escriben en una linealidad. La línea puede ser discontinua o continua $\mathrm{y}$, en este último caso, la violencia deviene de la consecuencia del conflicto. En otras palabras, el conflicto en ciertas condiciones puede dar origen a la violencia. En este caso, hablamos de conflictos que degeneran en violencias, por ejemplo, conflictos armados o guerras contra el narcotráfico.

Los conflictos parecen haber ganado terreno con un aumento de la violencia en los últimos años en todo el mundo. Lo que podemos llamar incremento de los grados de violencia, depende de las causas de determinadas actuaciones humanas que provocan que millones de personas no satisfagan sus necesidades, así los niveles productivos y tecnológicos lo permitan. Esto depende también de cómo son resueltos los conflictos, de los procesos y también del resultado de estos. Según Martín (2009) numerosos factores de riesgo interactúan unos con otros y crean condiciones propicias para que se desencadenen conflictos violentos. Estos factores se dividen de la siguiente manera.

Tabla 1. Factores de riesgo para desencadenar conflictos violentos.

\begin{tabular}{|l|l|}
\hline Factores políticos & $\begin{array}{l}\text {-la ausencia de procesos democráticos } \\
\text { - el acceso desigual al poder }\end{array}$ \\
\hline Factores económicos: & $\begin{array}{l}\text {-la distribución excesivamente desigual de los recursos, el acceso de- } \\
\text { sigual a los recursos, el control de los recursos naturales esenciales- el } \\
\text { control de la producción o comercialización de drogas }\end{array}$ \\
\hline Factores sociales y de la comunidad & $\begin{array}{l}\text {-la desigualdad entre grupos; } \\
\text {-la instigación al fanatismo de los grupos, aprovechando caracterís- } \\
\text { ticas étnicas, nacionales o religiosas; - la disponibilidad de armas pe- } \\
\text { queñas y de otro tipo. Es el caso de los indígenas. }\end{array}$ \\
\hline Factores demográficos & $\begin{array}{l}\text {-los cambios demográficos rápidos. Es el caso de la violencia urbana } \\
\text { en las grandes áreas metropolitanas. }\end{array}$ \\
\hline
\end{tabular}

Fuente: Elaboración propia a partir de Martín, 2009.

La Clasificación de la violencia de acuerdo a la Organización Mundial de la Salud (OMS) distingue tres tipos de violencia: La violencia auto infligida (comportamiento suicida, autolesiones); la violencia interpersonal (familia, pareja, menores, amistades, extraños) y la violencia colectiva. Es este último tipo el que nos concierne especialmente. 


\subsubsection{Violencia colectiva}

Para Krug, Dahlberg, Mercy y Zwi (2003), la violencia colectiva se define como:

(...) el uso de la violencia como instrumento por parte de personas que se identifican a sí mismas como miembros de un grupo -ya sea transitorio o con una identidad más permanente- contra otro grupo o conjunto de individuos, para lograr objetivos políticos, económicos o sociales (p. 235).

Por su parte, Buvinic, Morrison y Shifter (1999) han reconocido diversas formas de violencia colectiva según el hecho que hay un acto criminal o no como aparece en el cuadro siguiente.

Tabla 2. Crimen vs. violencia: ejemplos

\begin{tabular}{|c|c|l|l|}
\hline \multirow{4}{*}{ Conducta } & \multicolumn{3}{|c|}{ Definición legal } \\
\cline { 2 - 4 } & \multirow{4}{*}{ Violenta } & Robo a mano armada & Violencia no criminal \\
\cline { 2 - 4 } & Asalto & Violencia doméstica* \\
& $\begin{array}{l}|c| \\
\text { Violación por un desconocido } \\
\text { Asesinato }\end{array}$ & Violación marital* \\
\cline { 2 - 4 } & No & $\begin{array}{l}\text { Robo con allanamiento de morada } \\
\text { Crostitución } \\
\text { Soborno /corrupción }\end{array}$ & \\
\cline { 2 - 4 } & Violenta & -- \\
\hline
\end{tabular}

Fuente: Buvinic, Morrison y Shifter (2000: 4).

\subsubsection{La violencia política}

La violencia política es un tipo de violencia colectiva, pero con esta diferencia subrayada por Martín (1999):

(....) a diferencia de la acepción «violencia colectiva», la violencia política tiene más definido su campo semántico: la acción violenta de grupos organizados para modificar la estructura de poder, su distribución o la forma en que se ejerce. Se habla de violencia política cuando se puede atribuir a sus protagonistas un propósito relacionado con el poder y con sus principales protagonistas políticos: partidos, organizaciones, gobiernos o instituciones. La violencia política se entiende en estructuras propiamente políticas (p. 28-29).

Molina y Muñoz (2004) se interesan en la expresión de violencia e indican que:

Frente a otras formas de acción política, la violencia política se caracteriza por la utilización de la fuerza, es decir la utilización de este medio para quebrantar la voluntad de los representantes de una forma dada de gobierno, así como de la representación u organización social, de tal manera que se subvierten sus deseos e intenciones (p. 260).

Por su parte, Aróstegui (1994) menciona que la violencia política presenta históricamente una elevada gama de ideologizaciones y justificaciones, de estrategias o formas de ejercerse, de instrumentaciones $o$ de organizaciones ad hoc para ejercerla. El amplio campo de la violencia política comprende para muchos teóricos e historiadores un elevado número de manifestaciones: los motines, las huelgas, las rebeliones, insurrecciones, revoluciones, las represiones, los golpes de Estado, etc. Un elevado número de formas de ejercerse: resistencia, lucha armada, guerrillas, terrorismo, acción miliciana urbana, control social, persecución policial, y para otros teóricos pertenecen a este mismo género de fenómenos las guerras, los diversos géneros de guerras. También hay múltiples instrumentaciones: células, 
bandas, organizaciones guerrilleras, sectas, organizaciones paramilitares de partido, cuerpos policiales, ejércitos. Incluyen también las guerras, el terrorismo y otros conflictos políticos violentos que ocurren dentro de los estados o entre ellos, la violencia perpetrada por el Estado, como el genocidio, la represión, las desapariciones, la tortura y otras violaciones de los derechos humanos y la delincuencia violenta organizada, como los delitos perpetrados por bandas de malhechores y las guerras de pandillas.

\section{ANÁLISIS DE LA VIOLENCIA POLÍTICA}

Volvamos ahora sobre la definición del conflicto de Bélanger y Lemieux (1996) mencionada en la primera parte. Esta definición subraya dos aspectos importantes: a) la negativa de estar sometida a un control incluso a una regulación y b) la capacidad diferenciada por acción de los individuos. Estos dos aspectos son constitutivos de la violencia y de la política y, por consiguiente, de la violencia política. La particularidad de una violencia política se explica posiblemente por una condición amplia y socialmente vivida, repartida, y abiertamente expresada. En consecuencia, la permanencia de la violencia política tiene una importancia igual que la misma existencia de la sociedad en acción, para su transformación. Según Touraine (1994), la violencia toma una naturaleza política cuando actores sociales casi se transforman en Estados que luchan contra otros Estados y se identifican con valores que son directamente amenazados por un enemigo definido, como el mal o la barbarie, por ejemplo. En esta caracterización, que pide prestada de los análisis de tendencia centro-periferia, la noción de Estado se vuelve ineludible en el análisis de la violencia que invierte el campo de política. ¿Pero, no es simplemente la violencia un hecho político? El tema de violencia política aparece en este marco como una negativa de política. La violencia, sobre todo cuando es compartida y colectiva, es política. Se trata de ver en ella un substrato más sustentable, que es la causa profunda de su manifestación, entonces, más que la violencia, lo que es importante es el factor político que le da origen. Para desenredar un hilo entre la madeja de análisis, significaciones e interpretaciones de las manifestaciones conflictivas, es en el hecho político mismo en el que hay que retrasarse.

Sobre los análisis que intentan explicar lo político y encontrar su existencia en la concepción hegeliana, y el justificante por esta última, debe indicarse que se retrasan al ver lo político como un lugar hegemónico - centro de racionalidad que define y regula, en el sistema político encarnado por un Estado, las demandas de una sociedad heteróclita que tiene intereses variados. Toda manifestación o movimiento social entonces está interpretado como una voluntad de acceso a la esfera política o al centro-Estado.

En esta perspectiva, encontramos la tesis de Touraine (1994) quien, al considerar la vida sociopolítica latinoamericana, representa una puesta de integración de dos sistemas de representación: el sistema social y el sistema político. Define la violencia política como un fenómeno inscrito en la realidad de las sociedades dependientes latinoamericanas, como un fenómeno de naturaleza dual que puede ser, o una parte -o el contrario-, de los regímenes nacionales-populares. Por otro lado, un concepto que es muy particular en los escritos de Touraine es la noción de Estado (incluso casi estados) que parece indicar que hay política solo en el seno del Estado o en sus representaciones: los regímenes.

También encontramos una forma de estigmatización de política que, en el caso de Galeano (1981), encuentra en el capitalismo, las funciones y el papel del poderoso, de un Tercero que vacía el centro-Estado de sus prerrogativas, imponiéndole sus leyes $\mathrm{y}$, por ahí, sujetando la sociedad a sus propios principios. Entonces, podemos comprender lo político solo en la perpetuación de las estructuras de despojos y de desposesiones de la sociedad latinoamericana.

Si permanece monopolista e «industrializando» como lo describía Lenin, el capitalismo imperialista actual se constituyó, con la complicidad de los gobiernos y de la burguesía local, en importador de capitales que laboraba en la descapitalización y el norte - americanización de la economía latinoamericana (Galeano, 1981: 284).

Así, según Lenin citado por Galeano (1981), la causa, el origen y las manifestaciones del hecho político residen en las estructuras de la expoliación y su práctica. Esta tesis es también compartida por muchos otros analistas, es el caso de Collombat (2005) que subraya que:

(...) las instituciones financieras internacionales (Banco mundial, Fondo 
monetario internacional) así como la Organización mundial del comercio (OMC) a partir de su fundación en 1993, por la puesta en ejecución de programas de inspiración neoliberal, han engendrado numerosos movimientos sociales en América latina (p.67) ${ }^{2}$.

La "financiación" globalizada y la tercera revolución industrial contribuyeron fuertemente a extender las huellas estructuralizantes del capitalismo. En América Latina, estas huellas tienen un carácter muy particular según Gutiérrez y Osorio (2008) que produce dos consecuencias importantes. La primera es estipulada como: a) según las recetas neoliberales, se trata entonces en América Latina de construir un Estado mínimo al cual se quita su papel de planificador, de empresario, de proveedor de servicios públicos, de redistribuidor de riquezas $\mathrm{y}$ de beneficios sociales y, finalmente, de mediador en las luchas de intereses y en los conflictos sociales. El segundo se deduce del cambio de centro como el autor lo subraya. b) Para conseguir la despolitización de las necesidades sociales, hay que trasladárselas del Estado al mercado. El instrumento para llegar allá es la separación de política y de lo económico y, en consecuencia, de lo social. Así, la política, perdiendo su capacidad de intervenir en lo económico, se hace un sistema funcional auto centrado. Se asegura y se protege la estabilidad económica frente a las políticas y las demandas sociales.

Con esto, comprobamos que el análisis, que es mutante, no evacua el modelo centroperiferia. Cardoso (1998) subraya que se acaba en la dictadura de los mercados que reemplaza las dictaduras militares y se regresa en fuerza la dominación americana aliada a las elites locales. En el perfeccionamiento actual de la economía, las regiones económicamente desarrolladas con fuertes capitales y las instituciones financieras mundiales se constituyen en centro. La periferia entonces está formada por regiones en desarrollo porque hay que promover la integración social. Sin salir de la teoría centro-periferia, esta concepción permite, no obstante, resituar el centro que se hace Centro-capitalismo mundial y, allí, lugares de violencia que pertenecen al tandeo SociedadEstado. El capitalismo se constituye, de facto, en un lugar de política que tiene por resultado una violencia inducida por la mano invisible de la economía y del comercio. Podemos concluir que la política es un fenómeno no especializado cuya manifestación hace recurso a un referente espacial y temporal bien definido.

\section{PROPUESTA DE UNA LECTURA SEGÚN EL MODELO CENTRO-PERIFERIA}

La generalización del capitalismo y el desplazamiento del centro no evacuan las cuestiones de revoluciones y proyectos nacionales de desarrollo, de una integración social que debe tener en cuenta la heterogeneidad social. A lo mejor, levantan más con agudeza la necesidad y la existencia de un centro nacional político que es el Estado, aunque este debe tener prerrogativas mínimas. En efecto, con un centro trasladado, las sociedades parecen haber perdido su existencia en el sentido hegeliano y los estados han perdido su hegemonía. Si la tesis de los defensores del centro capitalista tiene el privilegio de levantar las cuestiones relativas a la soberanía, también la cuestión de los derechos individuales debe ser abordada.

Se puede creer que, con un centrocapitalismo mundial, los ciudadanos han perdido sus aspiraciones, intereses, necesidades $y$, sobre todo, su derecho y deseo de expresarse. En consecuencia, si consideramos solo la perspectiva del centro mundial, ¿cómo vamos a considerar la sociedad en la escala de cada país, los grupos sociales y los individuos accionantes en la búsqueda de vivir juntos y construir su devenir colectivo?

\subsection{Discusión teórica a favor de una propuesta de lectura}

De la política definida por el marco de las alianzas y de las corrientes de pensamientos internacionales ${ }^{1}$, de las regulaciones y normas cuya huella sobre la sociedad da forma al retrato de síntomas semejantes y de vividos partidos, nos encontramos entonces dentro de los límites geográficos de los países, en sistemas bipartidistas. Sistemas donde el centro no queda al nivel del Estado, y donde la sociedad no está posiblemente más en la periferia, ¿dónde se hace política? Tanto los analistas, las alianzas internacionales, el Estado y la sociedad usan cada uno formas de expresión cuyo contenido asegura una inevitable reinvención

1.Es la tesis de los que sostienen que las crisis de América latina provienen de alianzas, actores y limitaciones.

2. Traducción libre de la autora 
de política. En consecuencia, este trabajo hace la siguiente hipótesis:

Lo político está en la articulación del individuo y del colectivo, del racional y del irracional, un proceso auto generador y un lugar de acción y poder que, sin límite, se reinventa. Esta reinvención obedece a factores nuevos o viejos, dominables y evolutivos o no, dominados o no dominables.

En su manifestación en el seno de los procesos sociopolíticos con poderes polinucleicos, de dominación, de exclusividad y de organización, la política participa en la reinvención de la acción colectiva, las reglas y las normas de vivir juntos y del devenir colectivo. Su explicación valora sobre todo los planes políticos, económicos, antropológicos, sociológicos y psicosociológico, entre otros. La investigación distingue tres partes: a) la política según los determinantes de los artículos; b) la política por el modelo centro-periferia; c) la propuesta de una segunda lectura de análisis.

\subsection{Lo político según sus determinantes}

Si con la globalización, la política se hizo un fenómeno no especializado, como se analizó en la problemática, hay que verlo como un espacio de expresión, un lugar de emergencia y de subjetividad. También hay que encontrar nuevas funciones en su explicación y analizar sus efectos en el espacio particular de América Latina. En consecuencia, es importante en primer lugar privilegiar las cuestiones de sentido y definir las dificultades particulares con las cuales nos confronta esta elección. Con el concepto de regímenes nacionales populares que es importante para Touraine (1994), el análisis de la violencia política en un enfoque centro-periferia dominante como lo mencionamos en análisis de la situación, presenta la acción colectiva según tres tipos de objetivos nacionales: acción nacional antiimperialista, integración nacional y lucha de clase modernizadora. Para estos tres objetivos, una nación, un pueblo o una sociedad se reorganizan creando nuevos polos o centros políticos de diferentes escalas espaciales.

Por ejemplo, esta reorganización acaba en varios grupos de acciones o lugares de expresiones políticas que son : a) el de las vanguardias revolucionarias menos sociales: es la tesis de los que sostienen que las crisis de América Latina provienen de alianzas, actores y limitaciones - es el caso del Caribe y de América central donde existe la distancia entre popularismonacionalismo revolucionario $y$ focos formas diversas no infranqueables; b) el de la guerrilla local - es el caso de Guatemala; c) el de los grupos de extrema izquierda y de la lucha de clases entre guerrillas y el gobierno; d) el comunitarismo revolucionario que representa formas de descomposición o de debilidad del sistema político - es el caso de los gobiernos comunistas libres en Colombia que valoriza las guerrillas (fuertes - débiles) pero no poniendo en marcha la gran movilización política. Para Touraine, una reorganización de tipo particular se encuentra en Cuba: es el foquismo o el castrismo, el movimiento de liberación nacional que se representa como una sucesión de liquidación de formas populistas de movilización política, de movilización políticomilitar de una integración burocrática de la población en los objetivos del poder central. Rompiendo con un movimiento democrático desarticulado roído por la ideología o con un Estado dictatorial, esta forma de reorganización mantiene una gran distancia entre la guerrilla y el movimiento de masa que tiene como objetivo: la rotura con la dominación, la construcción de la nación, la formación de un poder revolucionario concentrado y personalizado.

El análisis a la tendencia marxista, se retrasará por estudiar los movimientos sociales y los diversos eslabones de su integración en los lugares de poderes tales como el popularismo, la figura del pueblo, etc. (Torunczyk, et al., 2010). De su parte, Peñafiel (2008) recurriendo a la tesis de un popularismo estructurante y a sus raíces, distingue tres épocas históricas de su despliegue y muestra el papel jugado por la figura del pueblo en la constitución de las escenas políticas en cien años de historia: el período populista, el post-popularismo y el período de resurgencia política. El post-populista que se presenta en los años 80 y es favorecido por las marcas de numerosas relaciones dialogadas. Con la vuelta del popularismo en el curso de los diez últimos años, Peñafiel (2008) constata un abandono de la producción de las relaciones sociales y una vuelta al cierre tecno-administrativo de las escenas políticas. Las poblaciones excluidas se constituyen en sujetos protagonistas. El autor, crítico del modelo centro-periferia, encuentra el centro en la 
figura legitimada del pueblo como lo menciona: « la forma populista se encuentra por todas partes intensamente en América Latina porque la figura del pueblo está en el centro de la representación política en el curso de los cien últimos años de su historia» (p. 101). Es ella que deviene figura de la estabilidad y de los otros criterios impuestos por el contexto internacional. Pero, es transformada, sobre todo, por la lengua política y la soberanía individual. Peñafiel encuentra el origen de política en la lengua política. La representación de política alrededor de la figura del pueblo instituye la realidad social que crea y reproduce el pueblo. El discurso se hace allí en un fenómeno social que crea prácticas discursivas en un espacio y una temporalidad dados y se hace, en consecuencia, en una convergencia estratégica de posiciones divergentes. Las lenguas constituyen reglas comunes constitutivas de una comunidad que permiten la circulación de las estrategias narrativas. Los narradores ceden la plaza al pueblo y se borran. Un nuevo orden político se sustituye al antiguo: es el de la práctica discursiva y de las reglas de dispersión de la formación discursiva. El pueblo es accionante. Mismo si el pueblo es neutralizado, él conserva su poder como accionante. Es la figura de legitimación y de distribución de valor modal. Una serie de actores políticos buscarán legitimar su acción con arreglo al pueblo. El número de actores aumenta, la figura del pueblo y sus actores se hacen verdaderos, deseables y reproducen las prácticas discursivas (acciones e instituciones conforme con las pretensiones de los actores). El ejercicio del poder depende del poder y de contar con la competencia enunciativa. Estamos en el estatismo, en la legitimación del Estado o la anticipación prospectiva de su devenir.

¿Debemos comprender que el popularismo es la consecuencia de una frustración endógena? Sería muy ilusorio considerarlo como un conjunto de movimientos esporádicos. Aunque se consideran a menudo las manifestaciones del popularismo sobre el plan ideológico, la utilidad del fenómeno es innegable. En efecto, participa en el dinamismo de política. La perspectiva de Peñafiel coloca el centro en la sociedad y en la población. La figura legitima del pueblo aparece como el nuevo centro de poder y de racionalidad. Este será despojado, no obstante, por estructuras e instituciones del centro-Estado. Por lo tanto, expresará de modo inasequible la negativa de estar sometida a una regulación o representará la expresión de la capacidad diferenciada por acción del pueblo. Esta forma del inasequible es bien la prueba de la dinámica de la reinvención de política. En este tipo de manifestación del derecho a la ciudad y del poder plebeyo, la lengua tiene la naturaleza de organización, el discurso es fuerza de movimiento. Asistimos también a una nuclearización multiforme del pueblo y la multiplicación de los centros. El centro no es más el centro estático, se vuelve mutante construyéndose y suprimiéndose con las coyunturas políticas, nacionales o internacionales, con las aspiraciones y los canales para llevarlos a la realización. Con la lengua y el discurso, volvemos a una forma dinámica.

También para Negri y Cocco (2006), las tesis desarrolladistas y la dependencia son hoy caducas. El modelo centro periférico fue suspendido porque no supo innovar para imponer el mercado como espacio de movilización social. Los autores consideran que estas tesis hacen superficial un fenómeno que tiene raíces profundas y cuya explicación sube a la herencia oligárquica y colonial con la cual jamás hay rotura. A pesar de las causas históricas de los movimientos sociales, resulta que la situación singular incluso problemática de la sociedad latinoamericana es la misma fuente de su regeneresciencia y de su dinamismo.

La perspectiva histórica será también utilizada por Beaucage (2005) que hace, con la ayuda del trayecto del indianidad, un análisis antropológico de política y la acción social en América Latina. El autor nos coloca en una perspectiva antropológica y política y hace la hipótesis siguiente: " las construcciones fabricadas dominantes, creadas en lo imaginario y por las prácticas y las representaciones en la dinámica de las relaciones entre dominantes y dominados y según un trayecto triple teológico, antropológico y político" (p. 3) pueden ser explotadas por los dominados para crear nuevos movimientos. Del lado estatal y los dominantes, elaboramos políticas polarizadas donde el indígena siempre es visto como el débil. Históricamente, el discurso teológico da sus fundamentos al discurso político. Encontramos una definición de indianidad subrayando los sacrificios humanos, pero no nos interesamos por los potenciales de los habitantes del nuevo mundo. Luego, colocamos una ideología de la conquista que se inscribe en la Reconquista. Las vías de la colonización europea son múltiples. 
La teología del « mal indio «, el desarrollo rápido de las industrias mineras en NuevaEspaña y en Perú luego la refuncionalización forzada de las repúblicas de soplones (repûblicas de indios) proveedores de mano de obra con la regulación pública del corregidor que provocan la reestructuración social y espacial. Como consecuencia, conjuntos vastos y sociopolíticos son fragmentados en comunidades dotadas de una administración interna elegida (el cabildo) y dos castas distintas que evolucionan en el mantenimiento de la diferencia. En relación con la ideología del progreso, la definición política asociará al amerindio con superfluo, con ocupante provisional de un territorio. El modelo de Beaucage se presenta como una combinación de la tesis de los usuarios del modelo centroperiferia y de sus críticas. Sin referirse al enfoque centro-periferia ni situar el centro de poder, entramos con este autor dentro de las sociedades latinoamericanas por la dimensión de los recursos, los grupos y las interacciones sociales. Dentro de los Estados, encontramos una sociedad dividida en clases que sufren por fuera la influencia de la metrópoli colonizadora y se dan forma a merced de las mutaciones de esta última.

El ejemplo de la tesis de Peñafiel y la de Beaucage ofrece nuevas perspectivas: la utilización del discurso por las dominadas, el proceso de legitimación del pueblo y el proceso de formación del discurso. Por otro lado, encontramos allí un centro por fuera que no es el capitalismo sino la potencia colonizadora y sus mutaciones. Podemos ver que la política se presenta como un proceso irracional unas veces programada con determinantes irracionales. Es generado tanto por el colectivo allí dónde se encuentra una vía de expresión directa o por el individuo y, de momento, se encuentran unas vías y medios de expresión en y por el colectivo. Encontramos también, la importancia y el interés marcados para los discursos políticos por los cuales la política se vuelve especializada y hecha referencia. Sin entrar aquí en el detalle, subrayemos, una vez más con riesgo de quedarse englobante, la pertinencia de la escena internacional que vuelve decorado lo político de legitimación, y de la validación de las aspiraciones de los autóctonos. Por fin, observemos la utilidad y el uso con una agudeza singular de las representaciones por las causas políticas.

En suma, la política se imagina y se manifiesta por la articulación del individuo y de colectivo, del racional y del irracional. Obedece a factores dominables, evolutivos, pero igual cambiantes, factores todavía no controlados y no dominables. En su evolución, los países, a pesar de su singularidad, presentan un sistema político amordazado en sus instituciones y alianzas internacionales, cuajado en la regulación y las normas, viven al margen de un rol social que gasta todas las formas de expresión cuyo lenguaje es indecible o a veces violento cuya existencia es latente, implícita y explícita. En un proceso político bipartidista, encontraremos la clase dominante y su compañero excluido, de quien intenta muy a menudo escapar. No obstante, esta dualidad representa solo una forma simplista de política.

La política apoyada sobre el plan internacional presenta otras dimensiones que tienen, a menudo, más importancia, olvidando todas las dimensiones internas. ¿Por qué la política debe ser reparada privilegiando uno o el otro de estos polos? Con las perspectivas ofrecidas por los autores citados, la política es un espacio ilimitado dentro de una articulación positiva entre la representacióncontribución de los ciudadanos y la acción de los elegidos que tienen poder y función de representación. Contrapoderes que se autorizan, se invisten en una eficacia simbólica cuyo objetivo no es de suplirse a las instituciones de poder oficial Bourdieu (2002). No obstante, su poder esporádico no debe ser descuidado. ¿Qué decir de la lectura de la política presentada en la literatura y cómo comprender los factores importantes?

\subsection{Reflexión y propuesta de una lectura}

Con la perspectiva que el modelo centroperiferia queda todavía vivo a pesar de numerosas críticas, y considerando que política es un proceso polinucleico, auto generado, articulado por el colectivo y el individuo, un proceso que se reinventa sin cesar y que participa en los procesos sociopolíticos de dominación, de exclusividad y de organización, en la reinvención de la acción colectiva, las reglas y las normas de vivir juntos y del devenir colectivo. ¿Todavía podemos explicar la evolución de la política en América Latina por medio del modelo centro-periferia?

A pesar de las críticas, el modelo centroperiferia permanece presente en numerosos análisis. El ejemplo del modelo sistémico de 
Bertterlanfy, se constituye en la entidad de dos componentes. Esta dualidad predefine la clasificación de todos los factores de generación de la política y de la reinvención de la acción social devolviendo esta clasificación estática. Hay que clasificar en el centro todo lo que depende del conocimiento, las reglas, las normas y el funcionamiento - dependiendo del convenio social u otro - adoptados y respetados por todos. En la periferia, clasificaremos todo lo que es marginal, nuevo, espontáneo, no regulado. En tal proceso bipartidista encontraremos la clase dominante y su compañera - la sociedad excluida-, a la que siempre procura evitar. El análisis apoyado sobre el plan internacional intenta presentar la misma bipolaridad a una escala extendida. De este hecho, podemos fácilmente reducir la escala a individuos o grupos de individuos en la sociedad. A esta escala, la política es presentada con otras dimensiones que tienen tanta importancia como los factores conocidos habitualmente. No obstante, estas dimensiones no son tomadas en consideración por la dualidad que representa solo una forma simplista de un proceso muy dinámico.

En una lógica dinámica, la visión ideológica de centro de poder es vista de nuevo por Chevalier que escribe:

Así concebido, el modelo centro-periferia permite poner en evidencia la lógica que dirige el desarrollo de los procesos políticos; transportable a las órdenes diversas de realidad política, macro y microscópicas, abastece un marco general de análisis, en el que las implicaciones parecen particularmente ricas y el que puede, desde entonces, ser puesto a prueba sobre una serie de campos particulares de investigación (1978: 131).

En una lógica centro-periferia arraigada en la teoría del caos, disociada la interpretación económica de la dependencia, el centro es orden y la periferia es desorden. No obstante, estos dos elementos participan en la misma realidad y son inseparables: «se parasitan mutuamente: reflejando la división, la separación, la contradicción provocada por la aparición de un sistema organizado, quedan, como tal, unidas simbióticamente" (p. 128). Para Chevalier (1978), la constitución del espacio político es un proceso de co-construcción por la instancia dirigente y por la sociedad.
(..) el modelo centro-periferia se encuentra pues a todos los niveles políticos, bajo la forma de un corte fundamental entre un principio de orden y de cohesión, y elementos desordenados y disparatados. Este corte es a la vez desgarrador, en la medida en que introduce una división irreducible por la cual va a deslizarse el informe de dominación-sujeción, y necesario, ya que hace posible el trabajo político y asegura la reproducción del sistema: el sistema político teme aún menos a la muerte como es más activo y ya que los intercambios internos y externos entre ambos polos opuestos son más intensos (Chevalier, 1978: 15).

El autor sobrepasa la visión dual política / sociedad para retrasarse más bien los intercambios y las interacciones entre los sistemas (políticos y sociales). En un orden instituido, estos intercambios presentan dos aspectos contradictorios, en primer lugar el de la consideración de un sistema político global de reproducción de la sociedad sin control total y, en segundo lugar, el de los flujos moleculares que deriva de elementos moralizados endurecidos $u$ ordenados según el mismo plan de organización (partidos, sindicatos, administraciones) y "que circulan por los intersticios del poder vienen perturbarlo, minarlo, corroerlo y crean una tensión permanente" (Chevalier, 1978: 15).

Es en la articulación del individuo y del colectivo, del racional y del irracional el político se mueve obedeciendo a factores dominables, evolutivos, pero igualmente cambiantes, factores todavía no controlados y no dominables. En su evolución, los países a pesar de su singularidad, presentan un sistema político, amordazado en sus instituciones y alianzas internacionales, cuajado en la regulación y las normas, viviendo al margen de un rol social que gasta toda forma de expresión, cuyo lenguaje es indecible o a veces violento pero cuya existencia latente implícita y explícita asegura inevitablemente la emergencia. En esta perspectiva, la política se constituye en proceso político multipartito con poderes polinucleicos de organización, de dominación, de desestimación, de inclusión y de exclusividad. Es en la perspectiva con la que contamos y que nos empuja a elaborar un modelo que permita la segunda lectura política de las sociedades latinoamericanas. 


\subsection{Hacia la propuesta de una nueva lectura según el modelo centro-periferia}

$\mathrm{Si}$ el modelo centro-periferia en su forma dinámica todavía puede explicar el modelo político integrando las dimensiones - figura del pueblo, el discurso, la lengua y los lugares de expresión singulares. Para hacerlo, es importante invertir la pirámide del modelo centro-periferia. En efecto, la sociedad debe hacerse el centro de la política. En este caso, ¿cómo estructurar lo social?

Los modelos sociológicos sistematizan la reflexión alrededor de ambos ejes prioritarios: (1) las relaciones entre las estructuras y su funcionamiento, (2) los actores y sus poderes, los sistemas de dominación y de exclusión o la combinación de estos elementos. En los modelos emergentes -como el análisis estratégico de Crozier y de Friedberg (1977), el constructivismo estructuralista de Bourdieu (1987), la estructuración dual de Giddens (1987). - estos dos ejes son integrados según orientaciones variables entre ellos. Desde estos modelos, el análisis de la política puede hacerse observando las condiciones siguientes: (1) disociar el interaccionar del estructural en el social distinguiendo las diferentes funciones sociales; (2) estructurar o reestructurar el social según su modo de funcionamiento identificando los componentes que aseguran este funcionamiento. Para hacerlo, es importante distinguir dos dimensiones: (a) la estabilizante o «la estabilizadora» que da las indicaciones momentáneas de un mundo social, (b) la regeneradora y reformadora del génesis social existente de este mundo.

La dimensión estabilizante 0 «la estabilizadora" se compone de factores de contingencia de toda acción social. Son factores condicionantes como el espacio-tiempo que constituyen una dimensión ineludible de la acción según el modelo de Giddens. Están constituidos de: (1) el medio ambiente físico, el de los fenómenos físicos y químicos y los organismos vivos, que también es una dimensión espacial que no se integra en el sistema general de acción y, (2) la realidad, es decir la estructuración de las orientaciones significativas, incluidas las respuestas cognitivas que cumple el sistema cultural, que sirve de intermediario fundamental con la acción.
La dimensión estabilizante es también estructural. En el análisis estructural, la sociología de la acción articula, de buenas a primeras, la función de la regulación normativa de la acción que considera ser asumida por las instituciones y los sistemas sociales. En los modelos del sistema político, encontramos las instituciones representativas de autoridad de la sociedad. Esta enumeración de las estructuras objetivas hace estática la concepción de las representaciones y estigmatiza la dimensión regeneradora. Para Giddens (1987), estas estructuras constituyen más bien un conjunto de relaciones de transformación como propiedades de sistemas sociales. Según Bourdieu (1987), hay que distinguir dos tipos de estructuras: (1) las estructuras objetivas independientes de la conciencia y de la voluntad de los agentes quienes son capaces de orientar o de forzar sus prácticas o sus representaciones; (2) las constructivistas de un génesis social que existe en el mundo social mismo. Esta segunda dimensión se constituye, según el autor, de ambos factores que son: (1) el habitus y (2) los campos. Esta diferenciación cartesiana - materia versus espíritu- vuelve a aceptar el carácter racional de ciertas estructuras y el carácter difuso de otros. En efecto, como lo subraya Bourdieu (1987), el habitus son unos esquemas comunes de percepción, de pensamiento y de acción, disposiciones socialmente adquiridas que corresponden a un conjunto sostenible $\mathrm{y}$ transportable de esquemas que afectan los comportamientos y las actitudes. Son, según di Méo (1991) productoras y producidas de la historia, las prácticas individuales y colectivas. Constituyen elementos de permanencia. También son elementos de transformación como lo subraya el autor:

el pasado sobrevive pues en el actual, tiende a perpetuarse en el futuro, pero se actualiza constantemente bajo la forma de prácticas estructuradas, «a través de las cuales se ejercita continuamente la ley de las necesidades externas». Así se renuevan y se reconstruyen los esquemas de percepción, de pensamiento y de acción (Di Méo, 1991: 256).

La interpretación y la comprensión del habitus reenvían una a la otra dimensión, es decir la de la incertidumbre. Pélabay (2001), con este fin, subraya que la noción de habitus reenvía a esta ineludible interpretación de la regla a una forma de comprensión a la vez situada, circunstanciada, 
y voluntaria. La comprensión de las prácticas depende de su inscripción en el tiempo y en el espacio. Esta naturaleza espacio-temporal le permite a Taylor, citado por Pélabay. insistir en el hecho que la acción se sitúa siempre en la incertidumbre.

Hacer abstracción del tiempo y del espacio de la acción vuelve a pasar al lado del sentido de las prácticas. Toda acción significativa, aunque es dictada por una regla debe hacer frente a una incertidumbre que puede producir cambios en la realización de una práctica común. Al mismo tiempo, la incertidumbre hace el intercambio social más rico, pero igual muy angustioso Pélabay (2001: 198).

El concepto de incertidumbre también constituye un elemento central en la explicación del juego de los actores en casa de Crozier y Friedberg (1977: 215). Para estos autores, la incertidumbre (particularmente la relativa a situación de conflicto) genera el poder, la dependencia y la desigualdad. La incertidumbre puede ser una limitación, una oportunidad o hasta considerada como un fin o un objetivo que se interesa a reducir o a extender. En estos diferentes casos, permite comprender las causas y la naturaleza de la acción, el comportamiento de los actores según las circunstancias $y$, las estrategias puestas en ejecución. Giddens concibe las reglas de la vida social como las "técnicas o los procedimientos generalizables empleados en la actualización y la reproducción de las prácticas sociales" (1987: 70).

El ejemplo de las relaciones sociales, constituyen una dimensión de la acción. Son a la vez las condiciones y los resultados de las actividades cumplidas por agentes que forman parte del sistema. Para Crozier y Friedberg (1977), hay que distinguir las reglas del sistema y las reglas de las relaciones que se dan entre los actores para resolver los problemas diarios de la organización. Como tales, las reglas se constituyen de elementos estables y fundamentales y de elementos cambiantes. Las reglas fundamentales como las que definen el contexto legal van a cambiar más lentamente en la base de los arreglos, los convenios y las normas o las reglas más detalladas de los pisos superiores de la sociedad. Volveremos sobre estos aspectos en la parte subsecuente que se referirá en las lógicas de interpretación de las representaciones.
A ejemplo de las reglas, los recursos y el sistema cultural participan en el estructural. Esta es a la vez apremiante y, según Giddens, reenvía conjuntamente a las nociones de limitación y de competencia. El estructural, en casa de Giddens, no es estático. Se inscribe en una tríada teórica que lo disloca en tres dimensiones: estructural fruto de la acción, estructural forzada y estructural oportunidad. Esta tríada estructural es mudada por otra tríada, funcional esta vez, que se constituye de la función de generación, la función de regulación y la función de reproducción. En este caso estructural de Giddens, encontramos las normas, las reglas y los recursos en su aspecto dinámico e inducido. Bélanger y Lemieux (1996), reenvían los contextos de poderes, de intereses, de lucha, de conflictos. La movilización de los recursos va a constituir un motivo de lucha de poderes y de intereses que oponen las partes en presencia, se consagran un sentido a su ganancia o pérdida del control. Actores que buscan racionalmente sus intereses y ventajas y sus coaliciones que tienen en el monopolio del poder, y en la representación de los intereses y el control exclusivo van a andarse con rodeos a la objetividad de la representación. La cuestión de los recursos tanto para administrar como para buscar- puede crear una dependencia frente a otras estructuras y debilitar el principio de soberanía.

Para las doctrinas marxistas, los recursos establecen también un contexto objetivo donde se registran las limitaciones desigualmente sufridas según el rango, el haber, el saber y el poder. El problema de todos se hace en la movilización de los recursos para conseguir las contribuciones que se necesitan, Simmel (1992). El poder también es el poder de asignaciones de los recursos. En suma, todo en la dimensión estabilizadora es fuente de poder sean las reglas, los recursos, las estructuras mismas, el conocimiento, los valores y la incertidumbre. Sin embargo, es en la interacción que reside la manifestación del poder. Justo en la acción social cercada en la diferenciación que le deja una plaza ancha al actor que se expresa el poder. Así, el campo de acción constituye en cuanto a él, un campo que hay que explorar.

La dimensión estructuralista o
"estructuralizante" es una dimensión
subjetiva donde se elaboran y se manifiestan
interactivamente las respuestas y las reacciones.
Encontramos en esta dimensión, el discurso y
la lengua de Peñafiel (2008). En las tendencias


marxistas, fuertemente subrayadas, se privilegian las relaciones sociales en el seno de los cuales se organizan las relaciones de producción y de reproducción social. La reproducción en el sentido de Giddens es una modalidad del anclaje sociocultural. Es un sistema homeostático que Giddens define como sigue: «el sistema homeostático de reproducción puede concebirse como un conjunto de rizos causales en los cuales las consecuencias intencionales de acciones retroactúan, y reconstituyen las circunstancias iniciales que hicieron posibles estas acciones" (1987: 77). El modelo explicativo de la reproducción de Giddens presenta tres conceptos centrales de la gestión sistémica y de la estructuración. (1) La estructural y las estructuras, definidos por las reglas, los recursos o un conjunto de relaciones de transformación como propiedades de sistemas sociales que hacen caso omiso de la presencia del sujeto; (2) los sistemas sociales son definidos por las relaciones entre actores o colectividades, reproducidas u organizadas como prácticas sociales regulares; (3) la estructuración es el conjunto de las condiciones que rigen la continuidad o la transmutación de las estructuras. Incluye las modalidades del anclaje del estructural y de los sistemas sociales. En el estructural, encontramos la dimensión estabilizante de la representación tal como la hemos estudiado al punto precedente. Los sistemas sociales no son unos sistemas que simplemente rigen el marco de la acción, se mueven y se reproducen con arreglo de las relaciones y las actividades de los agentes $\mathrm{y}$ de las colectividades situados en el tiempo y en el espacio. Haciendo esto, participan en la estructuración de las condiciones que definen las modalidades del anclaje del estructural y de los sistemas sociales en la realidad tiempo-espacio.

La estructuración se define por las condiciones que rigen la continuidad o la transmutación de las estructuras y la reproducción de los sistemas sociales. En el estructural, encontramos las estructuras y sistemas sociales, es decir del tiempo, del espacio, recursos, reglas y relaciones. Estos conceptos son, en el sentido de Giddens, todas las contextualidades, es decir caracteres instituidos por la interacción o las dimensiones contextuales de la acción. De este hecho, existen, de una parte, una interdependencia entre las estructuras y los agentes y por otra parte interacciones entre agentes. La interacción y la interdependencia representan, ambas, un postulado aceptado por numerosos autores interaccionistas.
Moscovici (1994) hace una distinción entre la interdependencia de los individuos y sus interacciones. Comprueba que la primera es una realidad dada y la segunda una construida. Estos dos conceptos, comprendidos en la perspectiva integrativa, pueden ser explicados debido al principio de reciprocidad y de la integración de las actividades, con arreglo a la categoría de los actores, las relaciones de autonomía y de dependencia entre actores y de la reciprocidad de prácticas entre actores o colectividades (Giddens, 1987). La diferencia entre interdependencia e interacción se sitúa al nivel del contexto definido como arreglo de las variables espacio y el tiempo. Crozier y Friedberg (1977) añaden a la interdependencia, la noción de cooperación. A partir de una reflexión sobre la organización como un problema que hay que explicar como fenómeno artificial, el modelo de raciocinio de estos autores propone dos tipos posibles de integración para comprender la naturaleza y las dificultades de la acción colectiva: a) la sumisión impuesta o consentida por las voluntades parciales de los participantes en la voluntad y en los objetivos del conjunto (la limitación o su corolario, la manipulación afectiva y o la ideología); b) el contrato, es decir la negociación y el regateo que puede celebrarse de modo explícito tanto como implícito. En cambio, la interacción es introducida por la integración social. Supone una complementariedad funcional en que los actores pueden hacer caso omiso en el contexto global. Como si la unidad de los sistemas se reconstituye alrededor de entidades más pequeñas, la entidad considerada se constituye por los individuos - agentes, actores o sus pequeñas reagrupaciones. $\mathrm{El}$ agente es considerado en sus competencias o en su peritaje según sus posibilidades de control y de influencia. Esto conduce a relaciones que tienen un carácter asimétrico según Crozier y Friedberg (1977).

Esta asimetría es entretenida por el saber y la destreza que, ipso facto, fundan la autoridad. La proporción de autoridad y de influencia que se establece entre dos elementos es producida por la fuerza de una de ambas partes compensada por una debilidad de la otra parte en un campo dado (Pélabay, 2001). Para Crozier y Friedberg, toda relación al otro es estratégica. Contiene un componente de poder y es de una naturaleza conflictiva-colaborativa o competitiva. Esta visión del fenómeno conflictivo por la vía de la acción colectiva, las racionalidades y las estrategias individuales fuerza la reflexión 
sobre dos conceptos: el poder y el conflicto. El poder es la capacidad de producir resultados. Como tal, no es, un obstáculo a la libertad o a la emancipación de los actores. Al contrario, es el médium por lo cual se articulan sus acciones, hasta si posee propiedades apremiantes (Simmel, 1992). Según Crozier y Friedberg (ibíd.), el poder en el corazón de la cooperación es humano como una dimensión irreducible y normal de las relaciones humanas en el trabajo, para que sean armoniosos o conflictivos. Interviene en la formulación y la puesta en ejecución por los actores de estrategias deliberadas. Se expresa en términos de descubrimiento de las oportunidades diversas más o menos evidentes e inherentes a la posibilidad de asumir y de sostener las dificultades y los riesgos relativos a cada estrategia racional. Pero, la comprensión teórica de los fundamentos del comportamiento del actor encuentra, también, su explicación en las motivaciones de la acción, en los conceptos de la acción de control reflexivo, de la dialéctica del control o de la competencia. Para Giddens (1987), los actores saben lo que hacen y por qué lo hacen. Su competencia como actores depende más de la conciencia práctica. Esta es una ventaja tácita y el agente no puede siempre expresarla de modo discursivo.

El segundo nivel es el individual y psicológico del actor. Al nivel del actor, dos dimensiones pueden ser evocadas: la dimensión psicológica y la dimensión política. Para la dimensión psicológica, un ensayo de comprensión del conflicto puede ser pedido prestado de Sartre; que encuentra en la estructura de una relación la fuente de los mecanismos afectivos profundos y poderosos cuyo objetivo es el reconocimiento o la destrucción del otro. Crozier y Friedberg (1977) consideran que los problemas afectivos implican una relación de poder y de dependencia. Podríamos concluir la existencia de una implicación doble o de una equivalencia entre la estructura de la relación y los mecanismos afectivos. Estos autores sobrepasan, no obstante, esta dialéctica relacional ya que conciben que las elecciones de un individuo sean dictadas no solamente por sus propios objetivos, sino también por sus ventajas y su capacidad. Cada actor representa la realidad de otro modo según su plaza, su costumbre, su estrategia, su trayectoria personal y los intereses que son asociados a él. Con esta perspectiva, encontramos la influencia de las características intrínsecas del sujeto individual: competencias, conocimiento, saber y diálogo.

\section{CONCLUSIÓN}

La mayor parte de este articulo está dedicado a analizar los enfoques teóricos contenidos en los conceptos de conflicto, de violencia, de violencia política y de los hechos relativos a ellos. A lo largo de este análisis se ofrecen pistas que aconsejan la comprensión de los hechos en el contexto político y propone una perspectiva analítica de lectura con la teoría centro-periferia. Esta relectura tiene en cuenta los condicionantes simbólicos, ideológicos y culturales. En resumen, podemos decir que el político es un proceso policéntrico, cuyo desarrollo participa en la creación de nuevas órdenes de acciones o de nuevas formas de regularidad. Desde entonces, los procesos sociopolíticos se mueven hacia procesos de compromiso que hacen un esfuerzo por anclar la acción política en la construcción social. Sin embargo las metamorfosis, para el humano $\mathrm{y}$ en el último hacia el humano, tienen cada una la complejidad difícil de aprender según un solo modelo. Con la figura del pueblo, las movilizaciones sociales pueden, hacer frente a ciertas puestas, provocar un trastorno del orden político o el desplazamiento temporal de los lugares formales de poderes. En el análisis del contexto, importa subrayar el dinamismo del fenómeno político volviendo a definir el centro y la periferia. La sociedad tomada como centro presenta una lógica más inclusiva del análisis. Permite tener en cuenta factores nuevos. El poder deja de ser el determinante principal del análisis. El caso es entonces representársela tanto como un lugar de expresión como un accionante que contiene dos dimensiones: una dimensión estabilizadora o estabilizante y una dimensión estructuralizante. 


\section{BIBLIOGRAFÍA}

- Aróstegui, J. (1994). Violencia, sociedad y política: la definición de la violencia. Ayer, (13), 17-55

- Barrera, E. (2008). Globalización, geoestrategía y relaciones mundiales. Bogotá: Escuela Superior de Administración Pública. ESAP.

- Beaucage, P. (2005). Parcours de l'indianité: théologie, politique, anthropologie. Cahiers des imaginaires, (3).

- Bélanger, A. J., y Lemieux. V. (1996). Introduction à l'analyse politique. Coll. «Politique et économie». Montréal : Presses de l'Université de Montréal.

- Benjamín, W. (2012). Critique de la violence. En Corten, A., Huart, C., y Peñafiel, R. ed. L'interpellation plébéienne en Amérique latine: violence, actions directes et virage à gauche. Québec: Éditions Karthala, Presses de l'Université du Québec.

- Bourdieu, P. (1987). Choses dites. Paris: Ed. de Minuit.

- Buvinic, M., Morrison, A., y Shifter, M. (2000). Violencia en América Latina y el Caribe: Un Marco de Referencia para la Acción. En: Violencia en América Latina y el Caribe: Un Marco de Referencia para la Acción. Washington: BID.

- Cardoso de Mello, J. M. (1998). La vision centre-périphérie de Prebisch et la théorie du sous-développement de Celso Furtado. Cahiers du Brésil Contemporain, 33 (34), 73-78.

- Chevallier, J. (1978). Centre, périphérie, territoire. Paris : Presses universitaires de France.

- Collombat, T. (2005). Le mouvement syndical international dans les Amériques. État des lieux et enjeux, Travail, Capital et Société, 38 (2), 66-93.

- Crozier, M. et E. Friedberg. (1977). L'acteur et le système : les contraintes de l'action collective. Paris: Éditions du Seuil, 289 p.

- di Méo, G. (1991). L'homme, la société, l'espace. Paris: Anthropos.

- Observatorio Permanente de Riesgos Psicosociales. (2008). Violencia laboral en trabajo y sus manifestaciones. Madrid: Secretaria de Salud laboral y Medio Ambiente UGT. Recuperado de http:// www.fspmadridugt.org/dependencia/ documentacion/Guias\%20y\%20manuales/ Gu $\%$ C 3\%ADa $\% 20$ Violencia $\% 20$ en $\% 20$ el\%20trabajo.pdf.

- Friedberg, E. (1997). Le pouvoir et la règle : dynamiques de l'action organisée. $1^{\text {ère }}$ éd. 1993. Paris: Éditions du Seuil.

- Galeano, E. (1981). Les Veines ouvertes de l'Amérique Latine. Paris: Pocket.

- Garmendia Lorena, F. (2011). La violencia en América Latina. Anales de la Facultad de Medicina, 72, (4), 269-276.

- Giddens, A. (1987). La constitution de la société : éléments de la théorie de la structuration. Paris: Presses universitaires de France.

- Krug, E. G., Dahlberg, L., Mercy, J., Zwi, A., Lozano, R., et al. (2003)! Informe mundial sobre la violencia y la salud. Washington: Organización Panamericana de la Salud. Recuperado de: http://www.who.int/iris/ handle/10665/112670

- Moreno, F. (2009). Violencia colectiva, violencia política, violencia social. Aproximaciones conceptuales. Violencia y salud mental, 19. Recuperado de http://documentacion.aen. es/pdf/libros-aen/coleccion-estudios/violencia-y-salud-mental/parte1-algunos-conceptos-sobre-la-violencia/019-aproximaciones-conceptuales.pdf

- Morillas, J. M. M. (2003). Los sentidos de la violencia. Granada: Universidad de Granada.

- Martín, J. (2004) Qué es la violencia. En: B. Molina y F. Muñoz, ed., Manual de paz y conflictos. Granada: Universidad de Granada, 225-248.

- Moscovici, S. (1994). La société contre nature. Paris: Éditions du Seuil.

- Muñoz, F. A. y Molina, B. (2004). Manifestaciones de la violencia. La violencia política in Molina Rueda, B., \& Muñoz Muñoz, F. A. Manual de paz y conflictos. Universidad de Granada. p. 251-276. 
- Negri, A., y Cocco, G. (2006). Global: biopoder y luchas en una América Latina globalizada. Buenos Aires: Paidós.

- Gutiérrez, E. y Osorio, P. (2008). Modernización y transformaciones de las familias como procesos del condicionamiento social de dos generaciones. Última Década, (29), 03-135.

- Pélabay, J. (2001). Charles Taylor, penseur de la pluralité. Paris: Presses de l'Université Laval.

- Peñafiel, R. (2008). Le rôle politique des imaginaires sociaux: quelques enjeux théoriques autour de leur conceptualisation. Politique et sociétés, 27, (1), 99 - 128.
- Simmel, G. (1992). Le conflit. Paris: Circé.

- Torunczyk, D., Borgeaud-Garciandia, N., Penafiel, R., \& Tizziani, A. (2010). Penser le politique en Amérique latine : La recréation des espaces et des formes du politique.

- Canadian Journal of Latin American and Caribbean Studies, 35, (70), 273-275.

- Touraine, A. (1994). Qu'est-ce que la démocratie ? Paris : A. Fayard

- Guízar, F. (2009). Wixaritari (huicholes) y mestizos: análisis heurístico sobre un conflicto intergrupal. Latinoamericanistas Indiana, núm. 26, pp. 169-207. 